\title{
Temporal Horns: Balance Coils of Ventricular System in Acute Obstructive Hydrocephalus?
}

Temporal Hornlar: Akut Tıkayıı Hidrosefalide Ventriküler Sistemin Balans Bobinleri?

\author{
๑ Halil Önder ${ }^{1}$, (1) İ. Samet Daltaban ${ }^{2}$ \\ 'Yozgat City Hospital, Clinic of Neurology, Yozgat, Turkey \\ ${ }^{2}$ Bozok University Faculty of Medicine, Department of Neurosurgery, Yozgat, Turkey
}

Keywords: Temporal horns, acute obstructive hydrocephalus, cerebellar stroke, pathophysiology

Anahtar Kelimeler: Temporal hornlar, akut tıkayıcı hidrosefali, serebellar inme, patofizyoloji

\section{Dear Editor,}

Acute hydrocephalus associated with aqueduct obstruction is a major complication in cerebellar stroke syndromes that should be kept in mind among physicians because early and appropriate interventions can be lifesaving. An important point may be that, in some patient subgroups, despite the significant elevation of intracranial pressure, only a minor ventriculomegaly occurs in the acute period. Hence, some clinical remarks have been suggested in the early identification of acute obstructive hydrocephalus (1). For instance, enlargement of the lateral ventricles (especially, temporal horns), have been emphasized to be crucial in the diagnosis (1). Our first case was an 84-year-old male who was admitted with right-sided weakness (MRC: $4+/ 5$ ) and sensory deficit that started one day prior to admission. Cranial computed tomography (CT) showed unremarkable findings. Cranial magnetic resonance imaging revealed punctate diffusion restricted regions in the right hemisphere frontal and parietal lobes (Figure 1A). Treatments of subcutaneous low-molecular-weight heparin and aspirin 300 $\mathrm{mg}$ were $>$ administered. However, on the $2^{\text {nd }}$ day of follow-up, severe vertigo and vomiting started, and a rapid deterioration in his consciousness occurred. Cranial CT showed a large cerebellar hemorrhage that had developed in the interval period and acute hydrocephalus had occurred prominently in the bilateral temporal horns due to compression of the $4^{\text {th }}$ ventricle (Figure 1B). Hence, a ventricular catheter was inserted from the right fontal horn, which provided moderate improvement in the hydrocephalus (Figure 1C) as well as mild recovery in neurologic status [Glasgow Coma Scale (GCS) improved from 3 to 7 postoperatively].
The second case was a 71-year-old male who presented with ataxia and severe vomiting. A neurologic examination revealed severe truncal ataxia and left-sided dysmetria and dysdiadochokinesia. Cranial CT showed a mild left cerebellar hypodensity (Figure 2A). With the diagnosis of cerebellar ischemic stroke in the posterior inferior cerebellar artery territory, antiaggregant treatment was started. However, on the second day of follow-up, the neurologic findings deteriorated within a few hours up to GCS of 7 (eye: 1, verbal: 1, motor: 5). Repeat cranial CT showed a progression of the left cerebellar infarct with swelling and acute hydrocephalus (prominently in the temporal horns) due to the fourth ventricle obstruction (Figure 2B). The patient was transferred to the neurosurgery department for a shunt procedure. Occipital decompressive craniectomy and external ventricular drainage insertion were administered. Unfortunately, due to the brainstem compression and injury developing due to cerebellar edema in the subsequent period, no significant clinical improvement was achieved following the drainage procedure, the temporal horn enlargement was markedly recovered, however (Figure 3). The patient was evaluated as being in a chronic vegetative state in the follow-up at the third month in the intensive care unit. Subsequent edema following cerebellar strokes can resemble mass lesions in the posterior fossa, resulting in brain stem compression and obstructive hydrocephalus, which constitute the main complications of cerebellar stroke syndromes. In about $10-20 \%$ of patients with cerebellar infarct $(2,3)$, these complications are reported to occur, in which prompt surgical intervention may be the only treatment method. In light of these

\footnotetext{
Address for Correspondence/Yazışma Adresi: Halil Önder MD, Yozgat City Hospital, Clinic of Neurology, Yozgat, Turkey Phone: +90 5376836864 E-mail: halilnder@yahoo.com ORCID ID: orcid.org/0000-0002-1823-2278

Received/Geliș Tarihi: 18.12.2017 Accepted/Kabul Tarihi: 16.02.2018

${ }^{\circ}$ Copyright 2018 by Turkish Neurological Society

Turkish Journal of Neurology published by Galenos Publishing House.
} 


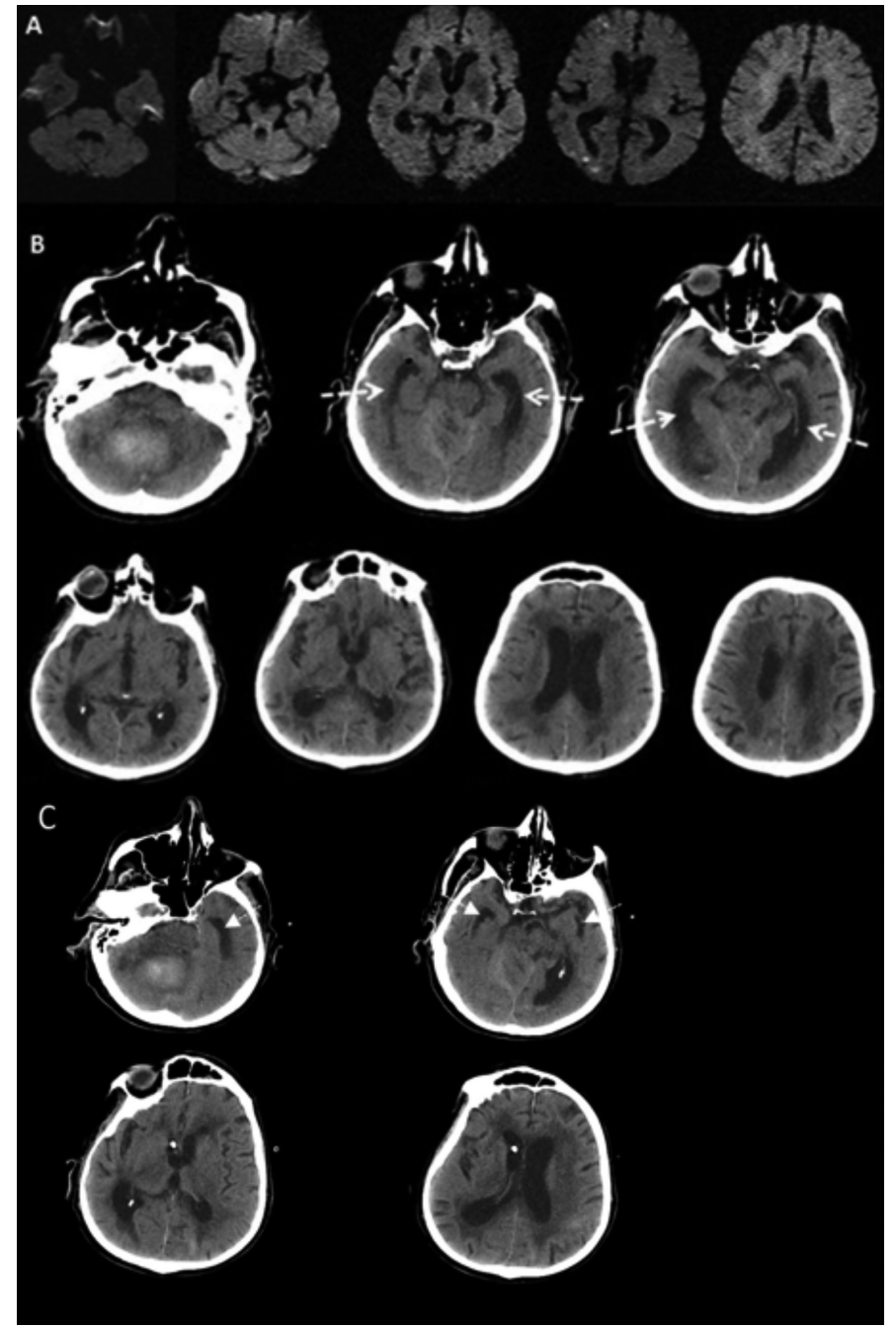

Figure 1. A) Cranial diffusion-weighted imaging sequences of patient 2 showing punctate diffusion restriction sites in the right hemisphere frontal and occipital lobes and normal ventricular system. B) Cranial computed tomography performed after clinical deterioration, showing acute hydrocephalus, asymmetrically prominent in bilateral temporal horns (arrows). C) Cranial computed tomography showing improvement of temporal horn enlargements following drainage procedure (arrows).

data, it can be understood that awareness of these complications as well as identifying signs of hydrocephalus in brain scans constitute critical points for physicians (1). Acute hydrocephalus can be diagnosed from the appearance of enlargement of the lateral ventricles, ballooning of the third ventricle, and increased diameter of the temporal horns (3). In our patients, CT showed prominent enlargement of the temporal horns, and post-shunt CTs showed a decrease in temporal horn diameters. The importance of temporal horn enlargement in the diagnosis of acute hydrocephalus has been emphasized several times in the literature (3). Nonetheless, to our knowledge, the mechanisms underlying these asymmetrical alterations of the ventricular system in the temporal horns in the acute period may be an interesting topic of discussion. In a report by Chen et al. (2), three patients with temporal horn entrapment
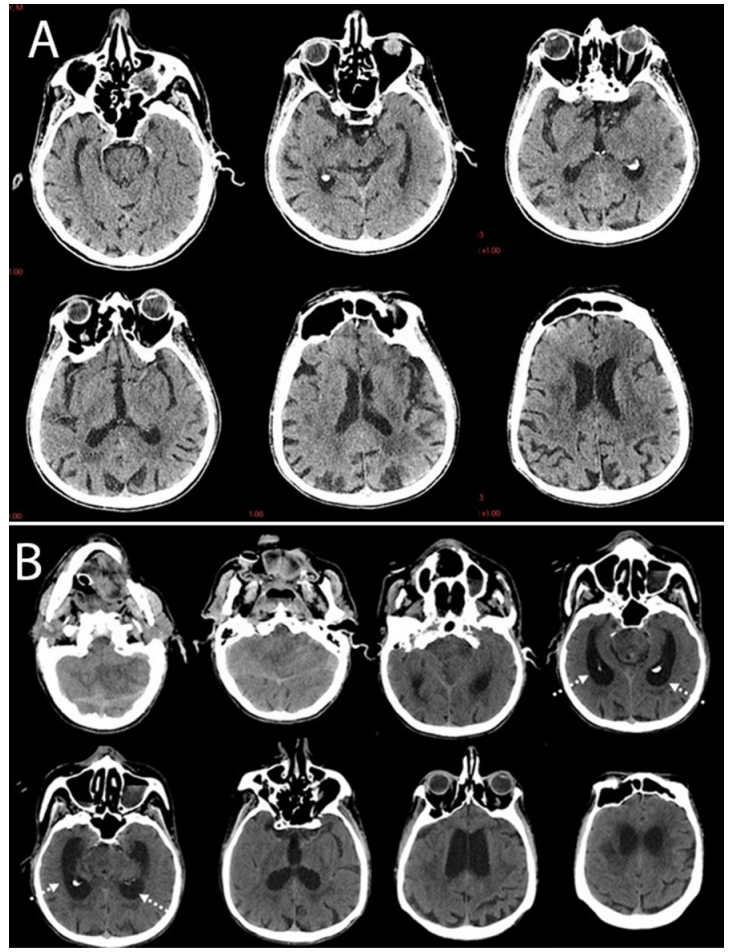

Figure 2. A) Cranial computed tomography of patient 1, showing brain parenchyma and ventricular system. B) Second Cranial computed tomography of patient 1 , showing acute obstructive hydrocephalus, which was prominent in bilateral temporal horns (arrows).

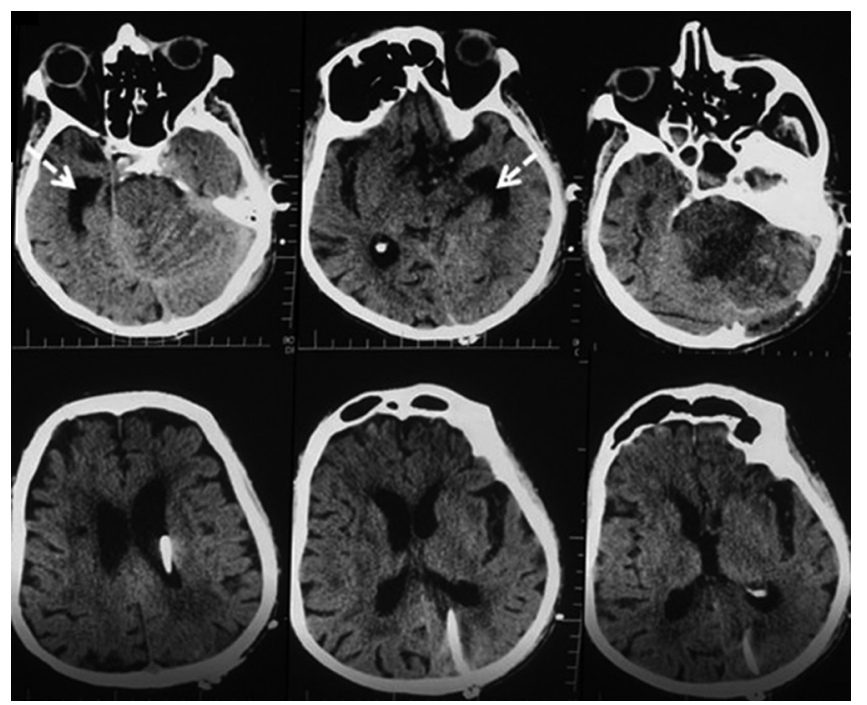

Figure 3. Cranial computed tomography of patient 1 after ventricular catheter insertion, showing significant normalization of temporal horn enlargements (arrows).

caused by primary malignant central nervous system tumors were illustrated. The authors showed resolution of symptoms caused by temporal horn dilatation following a simple technique of frontaltotemporal horn shunts. They also confirmed decompression of the temporal horns after this surgical procedure via serial imaging 
studies supporting the consideration of pressure increment in the temporal horns at presentation. It is my belief that this report (although the primary pathology of temporal entrapment is distinct from obstructive hydrocephalus) might give crucial perspectives regarding the mechanisms of CSF circulation in pathologic as well as physiologic circumstances. Future study results of larger case series might add essential perspectives regarding the CSF dynamics under physiologic circumstances as well as disturbed states. Hence, besides clinical approaches, clarification of these discussions may also add substantial data to help understand the mechanism of various diseases (in addition to acute obstructive hydrocephalus) leading to CSF circulation disturbances.

\section{Ethics}

Informed Consent: Consent form was filled out by all participants.

Peer-review: Internally peer-reviewed.

\section{Authorship Contributions}

Surgical and Medical Practices: H.Ö., İ.S.D., Concept: H.Ö., Design: H.Ö., Data Collection or Processing: H.Ö., İ.S.D., Analysis or Interpretation: H.Ö., Literature Search: H.Ö., İ.S.D., Writing: H.Ö.

Conflict of Interest: No conflict of interest was declared by the authors.

Financial Disclosure: The authors declared that this study received no financial support.

\section{References}

1. Brant WE, Helms CA. Fundamentals of Diagnostic Radiology. Lippincott Williams \& Wilkins, 2007.

2. Chen HJ, Lee TC, Wei CP. Treatment of cerebellar infarction by decompressive suboccipital craniectomy. Stroke 1992;23:957-961.

3. Mathew P, Teasdale G, Bannan A, Oluoch-Olunya D. Neurosurgical management of cerebellar haematoma and infarct. J Neurol Neurosurg Psychiatry 1995;59:287-292. 